\title{
The effect of gender, age and career orientation on digital dictionary use strategies
}

Gavriilidou, Zoe

Democritus University of Thrace, Greece (zoegab@otenet.gr)

Mavrommatidou, Stavroula

Democritus University of Thrace, Greece (stavrmav@hotmail.com)

Markos, Angelos

Democritus University of Thrace, Greece (amarkos@gmail.com)

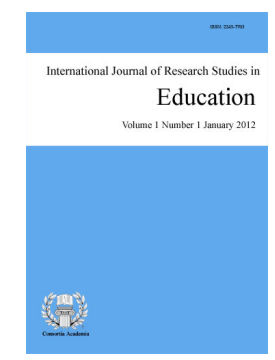

ISSN: 2243-7703 Online ISSN: 2243-7711

OPEN ACCESS

\section{Abstract}

The purpose of the present study was to investigate the profile of digital dictionary users as well as the effects of age, gender and career orientation on the use of digital dictionaries. A total of 1,141 individuals, aged 15-64 years old, participated in a large-scale empirical study. Data were collected through the online self-report questionnaire Strategy Inventory for Electronic Dictionary Use (SIEDU) which can be used to assess strategic use of electronic dictionaries and contains the following subscales: 1) familiarity with different types of electronic dictionaries and the conditions of their use; 2) strategies for lemmatization and acquaintance with dictionary conventions; 3) navigation skills; and 4) look-up strategies in new electronic environments. Results indicated significant main effects of gender and age on digital dictionary use, but a non-significant effect of career orientation. These results suggest that instruction for strategic dictionary use should be introduced in classroom so that appropriate dictionaries are used in all courses regardless of the field of study.

Keywords: dictionary use strategies; digital dictionary use; SIEDU; users' profile; career orientation 


\section{The effect of gender, age and career orientation on digital dictionary use strategies}

\section{Introduction}

Being a competent dictionary user requires several skills that "the user is assumed to possess, or can be expected to acquire, in handling a dictionary and making effective use of the information it contains" (Cowie, 1983, p. 136), called reference skills (Tomaszczyk, 1979; Roberts, 1997; Nesi, 1999; Nation, 2001; Lew \& Galas, 2008; Gavriilidou, 2013; Mavrommatidou, 2018b) or dictionary use strategies (Gavriilidou, 2013). This study explores the strategic profiles of digital dictionary users with the use of a self-report instrument, the SIEDU.

\section{Literature Review}

\subsection{Dictionary Use Strategies for paper or digital dictionaries}

A lot of skills are required on the part of the dictionary user to find the information being sought. For example, the ability to locate the unknown word or phrase in a text, decision on the appropriate form of the look-up item, awareness of dictionary lay-out, alphabetic sequencing or grammatical knowledge, ability to select the correct meaning, etc. are definitely required (Béjoint, 1981; Scholfield, 1982; Bogaards, 1994). Roberts (1997) also mentions the awareness of the various dictionary types and the specific categories of information found in different dictionary types, whereas Nesi (1999) in her study proposes a six-stage taxonomy of reference skills, including among other reference skills the decision whether dictionary consultation is necessary and the knowledge of lexicographical terminology. Therefore, researchers when using the term 'reference skills' focus on access as well as exploitation of information and appropriate dictionary consultation, according to the users' needs and conditions of dictionary use.

However, the skills necessary for the use of modern digital dictionaries are not necessarily the same as those of traditional print dictionaries. Some skills may not be transferred to digital products, because the electronic dictionaries may do part of user's job (Lew, 2013a). For example, they can automatically reduce an inflected form to a citation form or present compound words or idioms without having to search for each main element (Gavriilidou \& Mavrommatidou, 2016). Furthermore, the users may find the appropriate entry without having adequate knowledge of alphabetic sequencing or have the possibility to use more than one dictionary at once (Atkins \& Varantola, 1998; Nakayama \& Osaki, 2008).

On the other hand, the use of digital media requires new reference skills, which were not known while using print dictionaries. Students need personal judgment and thinking when choosing the lexical sources online (Rothenberg, 1997), acquisition of computer skills (such as vocabulary reading through pop-up windows, use of hyperlinks and non-linear presentation of data, skills in windows switching and searching, knowledge of different search techniques etc.) (Koren, 1997; Lee, 2000; Winkler, 2001; Engelberg \& Lemnitzer, 2009; Pastor \& Alcina, 2010; Lew, 2013b). Finally, lexical capabilities such as skimming and scanning as well as familiarity with the Internet terminology are required (Hargittai, 2005; Krajka, 2007; Tan, 2009).

This means that compared to print dictionaries, the use of digital reference tools requires a higher level of knowledge and skills that need to be transferred to pupils (Mavrommatidou, 2018a). The vast content of linguistic sources, the various retrieval options and the multiple functions require complex skills and new strategies (Krajka, 2007). It is not good enough to think that a student who often uses electronic reference tools is at the same time capable of doing it effectively (Wojtys, 2009; Mavrommatidou, 2018a). Therefore, it is necessary to discover the type of strategies digital dictionary users seem to apply the most and any possible correlations between dictionary use and age, gender and study fields. 
Gavriilidou $(2002,2012,2013)$ introduced the term dictionary use strategies (DUSs) to refer to reference skills, thus focusing on the conscious effort required by the dictionary user prior to, during and after the looking-up process and defines DUSs as 'techniques' that an effective dictionary user employs in order to perform a successful dictionary search.

Actually, DUSs are purposeful mental actions or behaviors that (paper or digital) dictionary users implement to meet successful word look-ups; they are complex and dynamic in nature, situated in a specific context, triggered by task demands and can be taught. The DUSs refer to user's active and intentional engagement during dictionary consultation by selectively attending to a look-up problem, mobilizing all available resources they have at their disposal (e.g. alphabetizing, lemmatizing, previous knowledge on dictionary types etc), deciding on the best available plan of action, implementing the decided steps, monitoring the performance and evaluating the look-up results for future action. The DUSs include a number of individual skills some of which are relevant in both electronic and print dictionaries, whereas others may be irrelevant or completely new in the digital means (Mavrommatidou, 2018b).

For example, a person in need of a dictionary (irrespectively if it's print or digital) has to be able to find the proper entry or the right subdivision of an entry and then retrieve the specific piece of information they need (meaning, spelling, pronunciation etc.) distinguishing relevant from irrelevant information (Gavriilidou \& Mavrommatidou, 2016). The need of understanding the definition of the unknown word, as well as phonetic symbols, grammatical information, derivative words, idiomatic expressions etc. is strongly emphasized in both types of dictionaries (Lew \& Galas, 2008). The role of the socio-cultural context in understanding and correctly interpreting meanings is also important.

Gavriilidou (2013) highlights the importance of the conscious dictionary use and the implementation of specific strategies in order to optimize the results and demonstrates the high correlation between dictionary strategy use and successful comprehension, text production or vocabulary acquisition.

In order to assess the self-reported dictionary use strategies, Gavriilidou (2013) created the Strategy Inventory for Dictionary Use (SIDU), which is a self-report valid and reliable tool that can be used for accurately profiling paper dictionary users' reported use in situated contexts and study the effect of users' individual characteristics such as gender, age, educational level, career orientation on overall dictionary use. SIDU measures a) dictionary use awareness strategies; b) strategies for dictionary selection and acquaintance with dictionary conventions; c) lemmatization strategies; and finally d) look-up strategies.

Using that instrument Chadjipapa (2018) investigated the reported paper dictionary use strategy profile of 745 students attending upper-elementary and junior-secondary schools in Greece and found a moderate overall mean score of reported dictionary strategy use. Moreover, her sample reported low to moderate strategy use with regard to the four individual types of strategies, with look up strategies having the highest mean score, followed by dictionary selection strategies, lemmatization strategies and dictionary awareness strategies, which were the least used strategies.

Given that digital dictionary use strategies may differ than those employed during paper dictionary look-ups, Mavrommatidou (2018b), based on previous research, created a digital self-report questionnaire, the Strategy Inventory for Electronic Dictionary Use (SIEDU), which includes a detailed list of the skills required for an effective use of digital dictionaries, for profiling digital dictionary use. SIEDU includes 32 items divided into the following subscales: 1) familiarity with different types of electronic dictionaries and the conditions of their use; 2) strategies for lemmatization and acquaintance with dictionary conventions; 3) navigation skills; and 4) look-up strategies in new electronic environments. SIEDU proved to be a valid and reliable tool of data collection, in order to check users' strategies in electronic dictionary searches, and can be used for research purposes, but also for the design of classroom-based intervention programs to increase the strategic use of dictionaries. Mavrommatidou (2018b) and Mavrommatidou, Gavriilidou and Markos (2019) report results regarding the compilation and validation of SIEDU. 
The use of self-report instruments like SIDU or SIEDU in pedagogical lexicography is very challenging because it offers data about what users believe they do when they perform dictionary consultations. Actually often, individuals may overestimate or under-estimate their look-up abilities and these misperceptions may negatively affect their will to change their practices during look-ups. Thus, from a methodological point of view, it would be necessary to complement previous research held with the use eye-tracking techniques or other research protocols (Galisson, 1983; Neubach \& Cohen, 1988; Whyatt, 2000; Simonsen, 2009; Kaneta, 2011; Simonsen, 2011; Tono, 2011; Lew, Grzelak, \& Leszkowicz, 2013; Lew, Kaźmierczak, Tomczak, \& Leszkowicz, 2017) investigating users' reference skills, problems and habits, when extracting information from digital dictionaries, with research on what users believe they do during look-up, in order to design and implement intervention programs raising users abilities to consult dictionaries. However, academic interest in self-reported DUSs is very recent. There appear to be limited studies offering dictionary use profiles and more precisely investigating strategies that successful dictionary users report they use-especially those who use digital reference tools. Only a few studies (Mavrommatidou, 2018a; Chadjipapa, 2018; Chadjipapa \& Papadopoulou, 2019) seem to have investigated DUSs across different academic disciplines or examined individual variation in terms of gender, age, educational level, etc.

\subsection{Gender}

Even though research has previously shown gender to be a parameter that affects language learning and use (Mulac \& Lundell, 1986; Biber, Conrad, \& Reppen, 1998; Mulac, Bradac, \& Gibbons, 2001; Mehl \& Pennebaker, 2003) as well as Language Learning Strategy Use (Oxford, Nyikos, \& Ehrman, 1988; Ehrman \& Oxford, 1989; Oxford \& Nyikos, 1989; Nyikos, 1990; Oxford, Park-Oh, Ito, \& Sumrall, 1993; Green \& Oxford, 1995; Dreyer \& Oxford, 1996; Kaylani, 1996; Mochizuki, 1999; Sheorey, 1999; Kazamia, 2003; Lan \& Oxford, 2003; Lee, 2003; Peacock \& Ho, 2003; Lee \& Oxford, 2008; Gavriilidou \& Psaltou-Joycey, 2009; Psaltou-Joycey \& Kantaridou, 2009; Mitits \& Sarafianou, 2012; Psaltou-Joycey, Sougari, Agathopoulou, \& Alexiou, 2014), there is, up to date, no research investigating how gender differentiates reference skills or affects the strategic dictionary use, with the exception of Chadjipapa (2018) who examined the effect of gender on DUS. Her study investigated only print dictionary use strategies.

Chadjipapa's (2018) study sample consisted of 745 pupils aged 10-15 years old. Dictionary use was evaluated by using the self-report questionnaire SIDU (Gavriilidou, 2013). In this study, girls only in secondary school reported using more dictionary strategies than boys. There were no significant differences found among genders in elementary school. At this particular age, both genders reported using dictionary strategies almost to the same extent. Therefore, gender seems to influence dictionary strategy use only in one level of education (secondary school), but it seems it is not independent from other variables, such as age or class. Also, the analysis showed that girls seemed to use look-up strategies and strategies for dictionary selection and acquaintance with dictionary conventions more commonly, contrary to lemmatization strategies and dictionary use awareness skills that were less frequently used by them.

In the same line, Chadjipapa, Gavriilidou, Markos \& Mylonopoulos (2020, p. 11) maintain that gender is not a strong predictor of Dictionary Use Strategies.

\subsection{Age}

Apart from gender, age and proficiency level are also main variables that may affect dictionary use. Previous studies examining dictionary use found that novice students use dictionary more frequently than advanced ones (Ibrahim \& Zalessky, 1989; Knight, 1994), although sometimes without success (Bensoussan, Sim, \& Weiss, 1984; Neubach \& Cohen, 1988). In the same line, Chadjipapa (2018) found that upper-elementary pupils in Greek schools reported using more dictionary strategies, compared to junior-secondary school students, however older pupils used more sophisticated strategies. 
On the other hand, Mavrommatidou (2018a) conducted a study with 700 participants (junior secondary, university students as well as teachers) coming from various Greek cities. She found that teachers and university students appear more familiar with the different types of electronic dictionaries and the conditions of their use compared to high school students. They also reported using the strategies for lemmatization and acquaintance with dictionary conventions as well as navigation skills to a significantly higher degree than pupils. The same is true in the case of look-up strategies in new electronic environments, although all participants exhibited low level of familiarity with them (Mavrommatidou, 2018a). In fact, teachers seemed to use the most strategies of all, contrary to pupils who reported the worst performance.

\subsection{Career orientation}

Career orientation may be an important factor affecting dictionary use strategies, since it may reflect different formal instruction. For instance, students in classics and humanities (foreign language teaching, philology, education, translation, linguistics, etc.) are incited to use dictionary regularly as part of their training in contrast with students in science, business, etc. However, except for Mavrommatidou (2018a), who explored the Frequency and the Type of Users' Digital Skills, there is to our knowledge no other research focusing on pedagogic lexicography that investigates the direct effect of career orientation on dictionary use.

Mavrommatidou (2018a) found no statistically significant differences in the use of the electronic dictionaries across study fields. The study participants were 376 undergraduate students coming from various disciplines and studying different subjects (mother tongue, foreign languages, math, economics, psychology, etc.). The results showed that undergraduate students of humanities did not employ different D.U.S. compared to those who attended science (e.g. math, economics, physics and biology). In fact, there were very small differences reported in all subscales (Familiarity with different types of electronic dictionaries and the conditions of their use; Strategies for lemmatization and acquaintance with dictionary conventions; Navigation skills; Look up strategies in new electronic environments).

\section{Aim, Research Questions, and Hypotheses}

The aim of the present study was to examine the profile of overall self-reported strategic dictionary use of the participants during digital dictionary consultation and investigate whether factors such as age, gender and career orientation influence digital dictionary strategy use. For this reason, we posed the following research questions:

Desearch Question 1: What is the frequency of self-perceived DUSs of the sample and the individual dictionary use strategies that participants report they use the most/the least during digital dictionary consultation? Considering previous research (Chadjipapa, 2018) on print dictionary use strategies we expect a moderate overall strategy use and low to moderate strategy use to the four different types of digital dictionary use.

$>$ Research Question 2: What is the effect of gender on dictionary use strategies? As mentioned in the Introduction, gender influences dictionary use with females using overall more frequently dictionary use strategies than males. Females are expected to report higher overall dictionary use strategies than males.

$>$ Research Question 3: Are there age-related differences in digital dictionary use strategies? In this case, we expect better results for adults compared to younger people.

Desearch Question 4: What is the effect of career orientation to overall strategic dictionary use? We expect that, given that students majoring in humanities get acquainted with dictionaries during their studies for functional reasons (translation of texts, etymologies etc.) they would report higher strategic dictionary use. 


\section{Method}

\subsection{Sample and Procedure}

The sample consisted of 1,141 individuals, participating in an online survey spread out in Facebook from February until the end of December 2017. Participants were included in the study by convenient sampling. The geographical distribution of the sample included participants coming from different regions of Greece (Kavala, Thessaloniki, Alexandroupolis, Xanthi, Athens, Komotini, Corfu, Ioannina, and Patra). In terms of gender, $68 \%$ were females and $32 \%$ were males, aged 15 to 64 years old. With regard to education, most of the participants were university students $(44.1 \%)$, followed by high school students $(36.3 \%)$, teachers $(13.3 \%)$, and university professors (3.4\%). Table 1 presents the demographic characteristics of the sample.

\section{Table 1}

Sample characteristics

\begin{tabular}{|c|c|c|}
\hline Factors & $n$ & $\%$ \\
\hline \multicolumn{3}{|l|}{ Gender } \\
\hline Female & 777 & 68 \\
\hline Male & 364 & 32 \\
\hline \multicolumn{3}{|l|}{ Age } \\
\hline $15-24$ & 756 & 66 \\
\hline $25-34$ & 180 & 16 \\
\hline $35-44$ & 107 & 9 \\
\hline $45-54$ & 70 & 6 \\
\hline $55-64$ & 28 & 3 \\
\hline \multicolumn{3}{|l|}{ Education Level } \\
\hline high school and vocational school students & 414 & 36 \\
\hline university students & 503 & 44 \\
\hline Teachers & 152 & 13 \\
\hline university professors & 39 & 4 \\
\hline others (public servants, freelancers, private employees) & 33 & 3 \\
\hline University students' career orientation $(n=503)$ & & \\
\hline $\begin{array}{l}\text { Humanities (Greek Philology, Foreign Languages (English, French, German, Italian, } \\
\text { Spanish, Turkish etc.), Philosophy, History, Psychology, Preschool Education, Primary } \\
\text { Education, Social Sciences) }\end{array}$ & 410 & 81 \\
\hline $\begin{array}{l}\text { Sciences (Economics, Physics, Mathematics, Medicine, Engineering, Biology, Business, } \\
\text { Computer Science) }\end{array}$ & 93 & 19 \\
\hline
\end{tabular}

\subsection{Instrumentation}

The instrument used to assess digital dictionary strategy use was the Strategy Inventory for Electronic Dictionary Use (SIEDU). The SIEDU is a valid and reliable electronic instrument for assessing Greek users' skills in electronic dictionary searches standardized through a rigorous psychometric protocol (Gavriilidou \& Mavrommatidou, 2016; Mavrommatidou, 2018b, Mavromatidou et al., 2019). It is a self-report questionnaire with 32 Likert-type items divided, as mentioned above, into the following subscales: 1) familiarity with different types of electronic dictionaries and the conditions of their use; 2) strategies for lemmatization and acquaintance with dictionary conventions; 3) navigation skills; and 4) look-up strategies in new electronic environments. Internal Consistency reliability for the overall scale and the four subscales was found to be very high (Table 2). These values indicate a high degree of internal consistency in the overall instrument and all sub-scales, showing that the instrument provides internally consistent scores. For a more detailed presentation of the creation and standardization of the instrument see Mavrommatidou et al. (2019).

The participants expressed their beliefs about the strategies they use during their digital dictionary searches, by answering the statements with a 5-point Likert scale, ranging from 1 ('never or almost never true of me') to 5

68 Consortia Academia Publishing (A partner of Network of Professional Researchers and Educators) 
The effect of gender, age and career orientation on digital dictionary use strategies

('always or nearly always true of me'. In this way we gathered information about their look-up strategies, their navigation skills, their degree of familiarity with different types of electronic dictionaries and the conditions of their use as well as their acquaintance with dictionary conventions and lemmatization techniques. Respondents who answered "never" to the first two questions, that is with no previous experience of electronic dictionary use, were omitted from further analyses due to unreliable responses.

Table 2

Internal consistency reliability (Cronbach's alpha values) for the SIEDU

\begin{tabular}{|c|c|c|}
\hline Subscale & Items & Cronbach's $a$ \\
\hline 1. Familiarity with different types of electronic dictionaries and the conditions of their use & 11 & 0.80 \\
\hline 2. Strategies for lemmatization and acquaintance with dictionary conventions & 8 & 0.76 \\
\hline 3. Navigation skills & 6 & 0.84 \\
\hline 4. Look-up strategies in new electronic environments & 7 & 0.83 \\
\hline (2) & 32 & 0.91 \\
\hline
\end{tabular}

\subsection{Data analysis}

Descriptive statistics (means and standard deviations) were computed to provide an overview of dictionary strategy use and identify the least and the most frequently used strategies. A series of independent samples t-tests and one-way ANOVAs corrected for family-wise error were also conducted to investigate the effects of gender, age and career orientation on electronic dictionary strategy use. Preliminary assumption testing was conducted to check for normality, homogeneity of variance and outliers. Cohen's $d$ and eta-squared $\left(\eta^{2}\right)$ were computed as effect sizes of mean differences among two and more than two groups, respectively. According to Cohen's (1988) definitions of effect size, small, medium, and large effects for $d$ are considered to be in the $0.20,0.50$, and 0.80 ranges, respectively, and for $\eta^{2}$ are 0.01, 0.06, and 0.14, respectively. In line with Oxford and Burry-Stock (1995), the five original response categories were collapsed into three levels, where a mean score of all participants in the range of 1 to 2.4 on a SIEDU item was considered to reflect low use of that strategy, 2.4 to 3.4 medium use and 3.5 to 5 high use. These cut-off points were arrived at by examining the distribution. All analyses were performed using IBM SPSS Statistics v21.

\section{Results}

\subsection{Strategic dictionary use}

The mean frequency of overall strategic dictionary use for the whole sample was found to reflect 'medium use' of strategies $(M=3.01, S D=0.68)$. The means for 'familiarity with different types of electronic dictionaries and the conditions of their use' $(M=3.24, S D=0.77)$ fell within the range of 'medium use', for 'strategies for lemmatization and acquaintance with dictionary conventions' $(M=2.82, S D=0.83)$ 'medium use', for 'navigation skills' $(M=3.52, S D=1.03)$ 'high use' and for 'look-up strategies in new electronic environments 'low to medium use' $(M=2.45, S D=0.78)$. The most frequently reported strategies were related to the knowledge of the different forms of digital dictionaries (e.g. online, in DVD-ROM or in a tablet), the ability of using search engines or typing specific URLs in order to find online lexicographical products and the navigation between different parts of lexicographic data. On the other hand, the use of different search techniques (e.g. Boolean search, Sound search, with Wildcards, etc.), the careful study of the abbreviation list and the use of 'Help' Menu were among the least frequently used strategies.

\subsection{Dictionary strategy use across gender}

A series of independent samples $t$-tests indicated that females exhibited a significantly higher degree of familiarity with different types of electronic dictionaries and the conditions of their use, as well as a higher degree of lemmatization strategy use and acquaintance with dictionary conventions, compared to males (Table 3 ). 
Gavriilidou, Z., Mavrommatidou, S., \& Markos, A.

However, no statistically significant differences were observed for the last two subcategories (navigation skills and look-up strategies in new electronic environments).

\section{Table 3}

Mean differences in electronic dictionary strategy use across gender

\begin{tabular}{lcccccccc}
\hline \multicolumn{1}{c}{ Strategy type } & Gender & $N$ & $M$ & $S D$ & $t$ & df & $p$ & $d$ \\
\hline 1. Familiarity with different types of electronic & Male & 364 & 2.99 & 0.81 & 7.625 & 1139 & $<0.001$ & 0.49 \\
dictionaries and the conditions of their use & Female & 777 & 3.35 & 0.72 & & & & \\
\hline 2. Strategies for lemmatization and acquaintance & Male & 364 & 2.61 & 0.86 & 5.858 & 1139 & $<0.001$ & 0.45 \\
with dictionary conventions & Female & 777 & 2.91 & 0.79 & & & & \\
\hline 3. Navigation skills & Male & 364 & 3.44 & 1.09 & 1.857 & 1139 & 0.064 & - \\
& Female & 777 & 3.56 & 0.99 & & & & \\
\hline 4. Look-up strategies in new electronic & Male & 364 & 2.44 & 0.86 & 0.117 & 1138 & 0.190 & - \\
environments & Female & 777 & 2.45 & 0.74 & & & & \\
\hline
\end{tabular}

The five reportedly most commonly used strategies for both genders were the following ones:

$>\quad$ I can find the dictionary I am looking for using a search engine (e.g. Google).

$>\quad$ I know what an online dictionary is.

$>\quad$ I know what an electronic dictionary in a mobile phone or tablet is.

$>\quad$ I use an electronic dictionary to find more easily the information I want (compared to a print dictionary).

$>\quad$ I use an electronic dictionary to look for the desired information more quickly (compared to a print dictionary).

The five strategies that were reportedly used the least by both genders were:

$>\quad$ Before using my new electronic dictionary, I carefully study the list of abbreviations (if there are any).

$>\quad$ To search for a word in an online dictionary, I perform a Boolean search (using AND, OR, NOT).

$>\quad$ To find a word in an online dictionary, I attempt sound search.

$>\quad$ I use an electronic dictionary in DVD-ROM or CD-ROM.

$>$ I use online dictionary available by subscription.

\subsection{Dictionary strategy use across age}

Means (standard deviations) of strategy use across different age groups are shown in Table 4. The results of one-way ANOVA and Bonferroni's post hoc multiple comparison test indicated statistically significant differences in electronic dictionary strategy use between participants of different age groups. More precisely the youngest age group (between 15 and 24 years old) reported using dictionary awareness strategies, as well as lemmatization and navigation strategies less frequently than the rest of the participants. However, no significant differences were found regarding the last subcategory (Look-up strategies in new electronic environments).

\section{Table 4}

Mean differences in electronic dictionary strategy use across age

\begin{tabular}{|c|c|c|c|c|c|c|c|c|}
\hline Strategy & Age & $N$ & $M$ & $S D$ & $F$ & $p$ & $\eta^{2}$ & Post-hoc \\
\hline 1. Familiarity with different types of electronic & $15-24$ & 756 & 3.00 & 0.58 & 81.05 & $<0.001$ & 0.095 & $\mathrm{G} 2>\mathrm{G} 1$ \\
\hline \multirow{3}{*}{ dictionaries and the conditions of their use } & $25-34$ & 180 & 3.66 & 0.77 & & & & $\mathrm{G} 3>\mathrm{G} 1$ \\
\hline & $35-44$ & 107 & 3.77 & 0.50 & & & & $\mathrm{G} 4>\mathrm{G} 1$ \\
\hline & $45-64$ & 98 & 3.61 & 0.53 & & & & \\
\hline \multirow{4}{*}{$\begin{array}{l}\text { 2. Strategies for lemmatization and acquaintance with } \\
\text { dictionary conventions }\end{array}$} & $15-24$ & 756 & 2.70 & 0.71 & 15.34 & $<0.001$ & 0.029 & G2> G1 \\
\hline & $25-34$ & 180 & 2.95 & 0.83 & & & & $\mathrm{G} 3>\mathrm{G} 1$ \\
\hline & $35-44$ & 107 & 3.13 & 0.91 & & & & $\mathrm{G} 4>\mathrm{G} 1$ \\
\hline & $45-64$ & 98 & 3.07 & 0.79 & & & & \\
\hline \multirow[t]{4}{*}{ 3. Navigation skills } & $15-24$ & 756 & 3.18 & 0.88 & 99.10 & $<0.001$ & 0.101 & $\mathrm{G} 2>\mathrm{G} 1$ \\
\hline & $25-34$ & 180 & 4.15 & 0.97 & & & & $\mathrm{G} 3>\mathrm{G} 1$ \\
\hline & $35-44$ & 107 & 4.26 & 0.70 & & & & $\mathrm{G} 4>\mathrm{G} 1$ \\
\hline & $45-64$ & 98 & 4.13 & 0.74 & & & & \\
\hline \multirow[t]{4}{*}{ 4. Look-up strategies in new electronic environments } & $15-24$ & 756 & 2.42 & 0.74 & 2.30 & 0.076 & 0.003 & $n s$ \\
\hline & $25-34$ & 180 & 2.45 & 0.83 & & & & \\
\hline & $35-44$ & 107 & 2.60 & 0.84 & & & & \\
\hline & $45-64$ & 98 & 2.55 & 0.78 & & & & \\
\hline
\end{tabular}

Note. G1=15-24, G2=25-34, G3=35-44, G4=45-64.

70 Consortia Academia Publishing (A partner of Network of Professional Researchers and Educators) 


\subsection{Dictionary strategy use across career orientation}

University students $(N=503)$ were further grouped according to their career orientation, i.e., in sciences or humanities. Independent samples $t$-tests showed that students in humanities are more familiar with different types of electronic dictionaries and the conditions of their use than students in sciences (Table 5). No significant differences, however, were observed in the frequency of use of lemmatization, navigation and look-up strategies.

\section{Table 5}

Mean differences in electronic dictionary strategy use across career orientation

\begin{tabular}{|c|c|c|c|c|c|c|c|c|}
\hline Strategy type & Career orientation & $N$ & $M$ & $S D$ & $t$ & $\mathrm{df}$ & $p$ & $d$ \\
\hline \multirow{2}{*}{$\begin{array}{l}\text { 1. Familiarity with different types of electronic } \\
\text { dictionaries and the conditions of their use }\end{array}$} & Sciences & 93 & 3.36 & 0.58 & \multirow[t]{2}{*}{-2.121} & \multirow[t]{2}{*}{501} & \multirow[t]{2}{*}{0.03} & \multirow[t]{2}{*}{0.24} \\
\hline & Humanities & 410 & 3.50 & 0.58 & & & & \\
\hline \multirow{2}{*}{$\begin{array}{l}\text { 2. Strategies for lemmatization and acquaintance } \\
\text { with dictionary conventions }\end{array}$} & Sciences & 93 & 2.93 & 0.75 & \multirow[t]{2}{*}{-1.164} & \multirow[t]{2}{*}{501} & \multirow[t]{2}{*}{0.24} & \multirow[t]{2}{*}{-} \\
\hline & Humanities & 410 & 3.03 & 0.70 & & & & \\
\hline \multirow[t]{2}{*}{ 3. Navigation skills } & Sciences & 93 & 3.77 & 0.87 & \multirow[t]{2}{*}{0.477} & \multirow[t]{2}{*}{501} & \multirow[t]{2}{*}{0.63} & \multirow[t]{2}{*}{-} \\
\hline & Humanities & 410 & 3.72 & 0.89 & & & & \\
\hline \multirow{2}{*}{$\begin{array}{l}\text { 4. Look-up strategies in new electronic } \\
\text { environments }\end{array}$} & Sciences & 93 & 2.50 & 0.79 & \multirow[t]{2}{*}{-0.350} & \multirow[t]{2}{*}{501} & \multirow[t]{2}{*}{0.73} & \multirow[t]{2}{*}{-} \\
\hline & Humanities & 410 & 2.53 & 0.74 & & & & \\
\hline
\end{tabular}

\section{Discussion}

The purpose of the present study was to examine the profile of overall self-reported strategic dictionary use of the participants during digital dictionary consultation and investigate whether factors such as age, gender and career orientation influence digital dictionary strategy use.

Regarding frequency of dictionary use strategies, we expected a moderate overall strategy use and low to moderate strategy use to the four different types of digital dictionary use. This hypothesis was partially confirmed. It was found that the sample reported moderate strategy use to three out of four subscales, in line with previous research (Chadjipapa, 2018, Chadjipapa et al., 2020). Participants appeared quite familiar with different types of electronic dictionaries and the conditions of their use, as well as with strategies for lemmatization and dictionary conventions. The sample reported 'high use' only for navigation skills, whereas slightly lower seems to be their performance regarding look-up strategies in new electronic environments. The high mean of navigation skills may indicate that the sample demonstrates a high degree of formal skills of navigation as a result of intensive use of computers, tablets, etc. in everyday life. The moderate overall strategy use highlights the need to implement intervention programs for raising users' strategies in order to achieve successful digital dictionary consultations.

Our aim was to also study the effect of gender on the self-reported frequency of dictionary use strategies. It was expected that girls would demonstrate significantly higher means in total and by strategy category. This hypothesis was partially confirmed. Statistically significant differences were found between men and women in two out of four subscales where girls outperformed boys: Familiarity with different types of electronic dictionaries and the conditions of their use and Strategies for lemmatization and acquaintance with dictionary conventions. This finding is in line with Chadjipapa (2018) and Chadjipapa et al. (2020) and may indicate that males and females have different preferences in terms of strategy use and employ different types of strategies.

Concerning the effect of age, it was expected to find better results for adults compared to younger people. This hypothesis was confirmed by the results that indicated that the youngest age group (between 15 and 24 years old) reported using dictionary awareness strategies, as well as lemmatization and navigation strategies less frequently than the rest of the participants. Furthermore, teachers and professors reported using dictionary strategies more often than students. This is probably due to the fact that, as part of the demands of their profession, teachers and professors have a daily practice with dictionaries, which makes them more experienced 
users. Another possible reason, stated by Peacock and Ho (2003), is that older students are less afraid of making mistakes than are younger ones, so they're probably more willing to experiment when using digital dictionaries. Furthermore, teachers' and professors' higher self-esteem, compared to students' lower estimated self-efficacy, may account for their better perceptions concerning digital dictionary use. We are fully aware that all these assumptions require further investigation.

No significant differences, however, were found regarding the last subcategory (Look-up strategies in new electronic environments). Although users may be aware of the content, circumstances and ways of using electronic lexicography products, due to their familiarity with the latest technological developments and the digital medium in general, they seem to have developed insufficient look-up strategies which require special knowledge and direct training (Mavrommatidou, 2018a).

Our final aim was to investigate the effect of career orientation. We expected that students majoring in humanities would report higher strategic dictionary use. This prediction was not confirmed by the data. The present study showed that there are no differences between students of different study fields, except for dictionary awareness strategies that students in humanities report using more compared to students in sciences.

Contrary to the fact that students majoring in humanities get acquainted with dictionaries during their studies, career orientation doesn't seem to affect their strategic use of digital dictionaries and more precisely the lemmatization, navigation, and look-up strategies they use. However, it does affect dictionary awareness strategies, because the acquaintance of students majoring in humanities with dictionaries may have helped them develop a dictionary culture and knowledge of the different types of digital dictionaries and the circumstances during which these can be used. On the other hand, probably their digital skills are not developed enough, so they are not able to outperform students of science in navigation skills or during the performance of look-up strategies in new electronic environments. More investigation is needed in order to have a better overall view about the skills and strategies applied when using digital dictionaries.

\section{Conclusions, limitations and further research}

The purpose of this large-scale study was to explore the strategies reported to be used by digital dictionary users and investigate the relationships between dictionary strategy use and career orientation, gender and age. The originality of the paper lies in the fact that it is a self-report research based on a rigorously standardized instrument that offers data about what users believe they do while they employ digital dictionaries. The major contribution of the paper is that the identification of digital dictionary users' profiles helps dictionary makers better understand user's skills, needs or misperceptions, thus contributing to the improvement of pedagogical dictionaries' content, according to these perceptions. The results have also some practical implications for classroom activities both for learners and teachers. Learners may overestimate or under-estimate their look-up abilities. These misperceptions may negatively affect their will to change their practices during look-up. Comparing what users believe they do during dictionary consultation with their actual behaviour is a way to identify and subsequently tackle such misperceptions through the creation of vocabulary integration programs and the design of special curricula for raising students' awareness on the strategic use of digital dictionaries.

The differences regarding age or gender should be taken into serious consideration by instructors who need to differentiate their treatment concerning strategies in the language classroom in order to lead their students to successful learning outcomes (Psaltou-Joycey \& Sougari, 2010). The more the teachers know about such factors as gender, age or discipline, the more readily they will be to handle with their students' individual differences in the classroom. 'Such knowledge is power -the power to plan lessons so that students with many different characteristics, including varied strategies, can receive what they need' (Green \& Oxford, 1995, p. 292).

We are fully aware of the limitations of this study. First, the findings regarding self-reported strategic use of digital dictionaries reported in this study need to be compared with results of other investigations using different research protocols in order to examine whether the reported use differs from the actual use. Second, the use of 
The effect of gender, age and career orientation on digital dictionary use strategies

self-report measures increases the risk of random, hasty and/or socially desirable answers and future research could benefit from the use of multiple sources. Furthermore, the generalizability of the findings beyond the study's sample is limited by the use of a convenient sample, mostly females with higher education. The findings should be interpreted with caution, since this study is cross-sectional in nature; future longitudinal studies or interventions may be more suitable for comparative investigation. Finally, future research on the use of digital dictionaries should investigate the effect of home ICT access as well as the influence of history of the sample using ICTs and digital dictionaries.

Acknowledgment - This research was approved by the 142/2-3-2015 decision of the Research Board of the Department of Greek of Democritus University of Thrace.

\section{References}

Atkins, B. T. S., \& Varantola, K. (1998). Monitoring dictionary use. In B. T. S. Atkins (Ed.), Using dictionaries: Studies of dictionary use by language learners and translators (pp. 1-45). Tübingen: Niemeyer. https://doi.org/10.1515/9783110929997

Béjoint, H. (1981). The foreign language students use of monolingual English dictionaries: A study of language needs and reference skills. Applied Linguistics, 2(3), 207-222. https://doi.org/10.1093/applin/II.3.207

Bensoussan, M., Sim, D., \& Weiss, R. (1984). The effect of dictionary usage on EFL test performance compared with student and teacher attitudes and expectations. Readings in a Foreign Language, 2, 262-276.

Biber, D., Conrad, S., \& Reppen, R. (1998). Corpus linguistics: Investigating language structure and use. New York: Cambridge University Press. https://doi.org/10.1017/CBO9780511804489

Bogaards, P. (1994). Tuning the dictionary to the skills of intermediate learners. Fremdsprachen Lehren und Lernen, 23, 192-205.

Chadjipapa, E., \& Papadopoulou, E. (2019). Profiling Greek teachers' dictionary use. Proceedings of 13th international conference on Greek linguistics (pp. 66-75). University of Westminister, London.

Chadjipapa, E., Gavriilidou, Z., Markos, A., \& Mylonopoulos, A. (2020). The effect of gender and educational level on dictionary use strategies adopted by upper-elementary and lower-secondary students attending Greek Schools. International Journal of Lexicography, 33(3), 1-20. https://doi.org/10.1093/ij1/ecaa012

Chadjipapa, E.-E. (2018). Investigation of the dictionary strategy use of primary and secondary school students [in Greek, Doctoral Thesis]. Democritus University of Thrace. Komotini, Greece.

Cohen, J. (1988). Statistical power analysis for the behavioral sciences (2nd ed.). Hillsdale, NJ: Erlbaum.

Cowie, A. P. (1983). The pedagogical/learners' dictionary: English dictionaries for the foreign learner. In R. R. K. Hartmann (Ed.), Lexicography: Principles and practice (pp. 135-144). London: Academic Press.

Dreyer, C., \& Oxford, R. L. (1996). Learning strategies and other predictors of ESL proficiency among Africaans speakers in South Africa. In R. Oxford (Ed) Language learning strategies around the world: Cross-cultural perspectives (pp. 61-75). Second Language Teaching and Curriculum Center: University of Hawaii.

Ehrman, M. E., \& Oxford, R. L. (1989). Effects of sex differences, career choice, and psychological type on adult language learning strategies. Modern Language Journal, 73(1), 1-13. https://doi.org/10.2307/327261

Engelberg, S., \& Lemnitzer, L. (2009). Lexikographie und wörterbuchbenutzung (4th ed.). Tübingen: Stauffenburg Verlag.

Galisson, R. (1983). Image et usage du dictionnaire chez les étudiants (en langue) de niveau avancé. In Etudes de Linguistique Appliquée, 49, 5-88.

Gavriilidou, Z. (2002). Investigating the reasons of dictionary use as a prerequisite for teaching strategic dictionary use in the classroom [In Greek]. Workshop proceedings: Teaching modern Greek as a mother tongue (pp. 45-59). Xanthi: Spanidi Editions.

Gavriilidou, Z. (2012). Construction, validity and reliability of the strategy inventory for dictionary use. In Z. 
Gavriilidou, A. Efthymiou, E. Thomadaki \& P. Kambaki-Vougioukli (Eds.), Selected papers of the 10th international conference of Greek linguistics (pp. 275-283). Komotini: Democritus University.

Gavriilidou, Z. (2013). Development and validation of the strategy inventory for dictionary use (SIDU). International Journal of Lexicography, 26(2), 135-153. https://doi.org/10.1093/ijl/ect007

Gavriilidou, Z., \& Mavrommatidou, S. (2016). Construction of a tool for the identification of electronic dictionary users' skills: Test specification and content validity. XVII Euralex International congress (pp. 168-178). Tbilisi.

Gavriilidou, Z., \& Psaltou-Joycey, A. (2009). Language learning strategies: An overview. Journal of Applied Linguistics, 25, 11-25.

Green, J. M., \& Oxford, R. L. (1995). A closer look at learning strategies, L2 proficiency and gender. TESOL Quarterly, 29(2), 261-297. https://doi.org/10.2307/3587625

Hargittai, E. (2005). Survey measures of web-oriented digital literacy. Social Science Computer Review, 23(3), 371-379. https://doi.org/10.1177/0894439305275911

Ibrahim, A.-H., \& Zalessky, M. (1989). Enquête: L'usage du dictionnaire. In A.-H. Ibrahim (Ed), Lexiques (pp. 24-30). Hachette, Paris.

Kaneta, T. (2011). Folded or unfolded: Eye-tracking analysis of L2 learners' reference behavior with different types of dictionary. In K. Akasu \& S. Uchida (Eds), Asialex 2011 proceedings. Lexicography: theoretical and practical perspectives (pp. 219-224). Kyoto: Asian Association for Lexicography.

Kaylani, C. (1996). The influence of gender and motivation on EFL learning strategy use in Jordan. In R. L. Oxford (Ed.), Language learning strategies around the world: Cross-cultural perspectives (pp. 75-88). Honolulu: University of Hawaii Press.

Kazamia, V. (2003). Language learning strategies of Greek adult learners of English. PhD Thesis, University of Leeds, UK.

Knight, S. (1994). Dictionary use while reading: The effects on comprehension and vocabulary acquisition for students of different verbal abilities. Modern Language Journal, 78(3), 285-299. https://doi.org/10.2307/330108

Koren, Sh. (1997). Quality versus convenience: Comparison of modern dictionaries from the researcher's, teacher's and learner's points of view. The Internet TESL Journal, 2(3).

Krajka, J. (2007). Online lexicological tools in ESP: Towards an approach to strategy training. Scripta Manent, 3(1), 3-19.

Lan, R., \& Oxford, R. L. (2003). Language learning strategy profiles of elementary school students in Taiwan. IRAL, 41, 339-379. https://doi.org/10.1515/iral.2003.016

Lee, K. (2000). English teachers' barriers to the use of computer-assisted language learning. The Internet TESL Journal, 6(12). http://iteslj.org/Articles/Lee-CALLbarriers.html

Lee, K. O. (2003). The relationship of school year, sex, and proficiency on the use of learning strategies in learning English of Korean junior high school students. Asian EFL Journal, 5(3), 1-36.

Lee, K. R., \& Oxford, R. L. (2008). Understanding EFL learner's strategy use and strategy awareness. Asian EFL Journal, 10, 7-32.

Lew, R. (2013a). From paper to electronic dictionaries: Evolving dictionary skills. In D. A. Kwary, N. Wulan \& L. Musyahda (Eds), Lexicography and dictionaries in the information age (pp. 79-84). Selected Papers from the 8th ASIALEX International Conference. Surabaya: Airlangga University Press.

Lew, R. (2013b). Online dictionary skills. In I. Kosem, J. Kallas, P. Gantar, S. Krek, M. Langemets \& M. Tuulik (Eds), Electronic Lexicography in the 21st Century: Thinking outside the paper (pp. 16-31). Proceedings of the ELex 2013 Conference, 17-19 October 2013, Tallinn, Estonia. Ljubljana/Tallinn: Trojina, Institute for Applied Slovene Studies/Eesti Keele Instituut.

Lew, R., \& Galas, K. (2008). Can dictionary skills be taught? The effectiveness of lexicographic training for primary-school-level Polish learners of English. In E. Bernal \& J. DeCesaris (Eds.), Proceedings of the XIII Euralex international congress (pp. 1273-1285). Barcelona: Universitat Pompeu Fabra.

Lew, R., Grzelak, M., \& Leszkowicz, M. (2013). How dictionary users choose senses in bilingual dictionary entries: An eye-tracking study. Lexikos, 23, 228-254. https://doi.org/10.5788/23-1-1213 
The effect of gender, age and career orientation on digital dictionary use strategies

Lew, R., Kaźmierczak, R. Tomczak, E., \& Leszkowicz, M. (2017). Competition of definition and pictorial illustration for dictionary users' attention: An eye-tracking study. International Journal of Lexicography, 31(1), 53-77. https://doi.org/10.1093/ij1/ecx002

Mavrommatidou, S. (2018a). Exploring the frequency and the type of users' digital skills using SIEDU. In $18^{\text {th }}$ EURALEX international congress (pp. 909-914). Ljubljana, Slovenia.

Mavrommatidou, S. (2018b). The creation and testing of the validity and reliability of a tool especially designed for the assessment of digital dictionary users'strategies: The strategy inventory for electronic dictionary use (SIEDU) [In Greek, Doctoral Thesis]. Democritus University of Thrace. Komotini, Greece.

Mavrommatidou, S., Gavriilidou, Z., \& Markos, A. (2019). Development and validation of the strategy inventory for electronic dictionary use (SIEDU). International Journal of Lexicography, 1-18. https://doi.org/10.1093/ij1/ecz015

Mehl, M. R., \& Pennebaker, J. W. (2003). The sounds of social life: A psychometric analysis of students' daily social environments and natural conversations. Journal of Personality and Social Psychology, 84(4), 857-870. https://doi.org/10.1037/0022-3514.84.4.857

Mitits, L., \& Sarafianou, A. (2012). Development of language learning strategies in multilingual vs. monolingual learners: Empirical evidence from a combined methods longitudinal case study. In Z. Gavriilidou, A. Efthymiou, E. Thomadaki \& P. Kambakis-Vougiouklis (Eds), Selected papers of the 10th ICGL (pp. 453-462). Komotini/Greece: Democritus University of Thrace.

Mochizuki, A. (1999). Language learning strategies used by Japanese university students. RELC Journal, 30(2), 101-113. https://doi.org/10.1177/003368829903000206

Mulac, A., \& Lundell, T. L. (1986). Linguistic contributors to the gender-linked language effect. Journal of Language and Social Psychology, 5, 81-101. https://doi.org/10.1177/0261927X8652001

Mulac, A., Bradac, J. J., \& Gibbons, P. (2001). Empirical support for the gender-as-culture hypothesis: An intercultural analysis of male/female language differences. Human Communication Research, 27, 121-152. https://doi.org/10.1111/j.1468-2958.2001.tb00778.x

Nakayama, N., \& Osaki, S. (2008). Dokkai ni okeru koukatekina denshijissho shidou wo mezashite: Jissho skill tokutei no tame no pilot chousa kara. 2nd Joint Conference on English Lexicography and Vocabulary, Chiba, Japan.

Nation, P. (2001). Learning vocabulary in another language. Cambridge: Cambridge University Press. https://doi.org/10.1017/CBO9781139524759

Nesi, H. (1999). The specification of dictionary reference skills in higher education. In R. R. K. Hartmann (Ed.), Dictionaries in language learning. Recommendations, national reports and thematic reports from the thematic network project in the area of languages, Sub-Project 9: Dictionaries (pp. 53-67). Berlin: Freie Universität Berlin.

Neubach, A., \& Cohen, A. D. (1988). Processing strategies and problems encountered in the use of dictionaries. Dictionaries: Journal of the Dictionary Society of North America, 10, 1-19. https://doi.org/10.1353/dic.1988.0018

Nyikos, M. (1990). Sex-related differences in adult language learning: Socialisation and memory factors. Modern Language Journal, 74(3), 273-287. https://doi.org/10.1111/j.1540-4781.1990.tb01063.x

Oxford, R. L., \& Burry-Stock, J. A. (1995). Assessing the use of language learning strategies worldwide with the ESL/EFL version of the strategy inventory for language learning (SILL). System, 23(1), 1-23. https://doi.org/10.1016/0346-251X(94)00047-A

Oxford, R. L., \& Nyikos, M. (1989). Variables affecting choice of language learning strategies by university students. Modern Language Journal, 73(3), 291-300. https://doi.org/10.1111/j.1540-4781.1989.tb06367.x

Oxford, R. L., Nyikos, M., \& Ehrman, M. (1988). Vive la différence? Reflections on sex differences in use of language learning strategies, Foreign Language Annals, 21, 321-29. https://doi.org/10.1111/j.1944-9720.1988.tb01076.x

Oxford, R. L., Park-Oh, Y. Ito, S., \& Sumrall, M. (1993). Japanese by satellite: Effects of motivation, language 
learning styles and strategies, gender, course level, and previous language learning experiences on Japanese language achievement. Foreign Language Annals, 26, 359-71. https://doi.org/10.1111/j.1944-9720.1993.tb02292.x

Pastor, V., \& Alcina, A. (2010). Search techniques in electronic dictionaries: A classification for translators. International Journal of Lexicography, 23(3), 307-354. https://doi.org/10.1093/ijl/ecq015

Peacock, M., \& Ho, B. (2003). Student language learning strategies across eight disciplines. International Journal of Applied Linguistics, 13(2), 179-198. https://doi.org/10.1111/1473-4192.00043

Psaltou-Joycey A., Sougari, A.-M., Agathopoulou, E., \& Alexiou, Th. (2014). The role of age, gender and L1 strategies in the L2 strategies of primary school children in Greece. In G. Kotzoglou, K. Nikolou, E. Karantzola, K. Frantzi, I. Galantomos, M. Georgalidou, V. Kourti-Kazoullis, Ch. Papadopoulou \& E. Vlachou (Eds.), Selected papers of the 11th international conference on Greek linguistics (pp. 1436-1448). Rhodes: University of the Aegean.

Psaltou-Joycey, A., \& Kantaridou, Z. (2009). Foreign language learning strategy profiles of university students in Greece. Journal of Applied Linguistics, 25, 107-127.

Psaltou-Joycey, A., \& Sougari, A.-M. (2010). Greek young learners' perceptions about foreign language learning and teaching. In A. Psaltou-Joycey \& M. Matthaioudakis (Eds.), Advances in research on language acquisition and teaching: Selected papers (pp. 387-401). Thessaloniki: Greek Applied Linguistics Association.

Roberts, R. P. (1997). Using dictionaries efficiently. 38th Annual conference of the American translators association (pp. 1-15). San Francisco, California.

Rothenberg, D. (1997). How the web destroys the quality of students' research papers. Chronicles of Higher Education, 43(49), 44.

Scholfield, P. (1982). Using the English dictionary for comprehension. Tesol Quarterly, 16(2), 185-194. https://doi.org/10.2307/3586791

Sheorey, R. (1999). An examination of language learning strategy use in the setting of an indigenized variety of English. System, 27(1), 173-190. https://doi.org/10.1016/S0346-251X(99)00015-9

Simonsen, H. K. (2009). Vertical or horizontal? That is the question: An eye-track study of data presentation in internet dictionaries. In Eye-to-IT conference on translation processes. Copenhagen Business School, Frederiksberg. http://www.cbs.dk/forskning/konferencer/eye_to_it

Simonsen, H. K. (2011). User consultation behaviour in internet dictionaries: An eye tracking study. In Hermes. Journal of Language and Communication in Business 24(46), 75-101. https://doi.org/10.7146/hjlcb.v24i46.97370

Tan, K. (2009). How effective is the electronic dictionary in sense discrimination? Lexikos, 19(1), $262-274$. https://doi.org/10.5788/19-0-439

Tomaszczyk, J. (1979). Dictionaries: Users and uses. Glottodidactica, 12, 103-119.

Tono, Y. (2011). Application of eye-tracking in EFL learners' dictionary look-up process research. International Journal of Lexicography, 24(1), 124-153. https://doi.org/10.1093/ijl/ecq043

Whyatt, B. (2000). A psycholinguistic investigation into the processes of comprehension and production: A decision making approach towards the preservation of meaning in translation [Ph.D. dissertation]. Adam Mickiewicz University.

Winkler, B. (2001). Students working with an English learner's dictionary on CD-ROM. In Information technology and multimedia in English language teaching conference (pp. 227-254). Hong Kong, The English Language Centre, The Hong Kong Polytechnic University.

Wojtyś, E. (2009). Towards effective dictionary use by L2 learners: In search of new perspectives. Lublin studies in modern languages and literature (pp. 169-179). Maria Curie-Skłodowska University, Lublin, Poland. 